\title{
The use of headspace solid phase microextraction for the characterization of volatile compounds in olive oil matrices
}

\author{
Laila H. Ribeiro ${ }^{a}$, Ana M. Costa Freitas ${ }^{b}$, Marco D.R. Gomes da Silva ${ }^{a}, *$ \\ ${ }^{a}$ REQUIMTE, Departamento de Química, Faculdade de Ciências e Tecnologia, Universidade Nova de Lisboa, 2829-516 Caparica, Portugal \\ b Departamento de Fitotecnia, Instituto de Ciências Agrárias e Mediterrânicas-ICAM, Universidade de Évora, Apt 94 7002-554 Évora, Portugal
}

\section{A R T I C L E I N F O}

\section{Article history:}

Received 12 February 2008

Received in revised form 22 May 2008

Accepted 29 May 2008

Available online 7 June 2008

\section{Keywords:}

Olive oil

Volatile compounds

Headspace

Solid phase microextraction

Kinetic absorption curves

\begin{abstract}
A B S T R A C T
Two different fibre coatings, for solid phase microextraction (SPME) sampling, poly(dimethylsiloxane) (PDMS) and poly(acrylate) (PA), were studied in order to test, for olive oil matrixes, two mathematical models that relate the directly proportional relationship between the amount of analyte absorbed by a SPME fibre and its initial concentration in the sample matrices. Although the PA fibre was able to absorb higher amounts of compounds from the olive oil sample, the equilibrium was reached later then with the PDMS fibre. In both cases, the amount of analyte present affected the time profile or the equilibrium time in two of the concentrations studied, $0.256 \mu \mathrm{L} / \mathrm{kg}, 2.56 \mu \mathrm{L} / \mathrm{kg}$ and for 2-ethylfuran, pentan3-one, pent-1-en-3-one, hexanal, trans,trans-non-2,4-dienal and in the four concentrations studied, $0.256 \mu \mathrm{L} / \mathrm{kg}, 2.56 \mu \mathrm{L} / \mathrm{kg}, 6.25 \mu \mathrm{L} / \mathrm{kg}$ and $400 \mu \mathrm{L} / \mathrm{kg}$, for 4-methyl-pent-3-en-2-one, 2-methylbutan-1-ol, methoxybenzene, hexan-1-ol, cis-hex-3-en-1-ol, trans-hex-2-en-1-ol, 2-ethyl-hexan-1-ol and trans,transdec-2,4-dienal. Comparing the mathematical models of both fibres, the PA-coated fibre showed direct proportionality between the initial concentration and amount extracted, that allows the possibility of relative quantification in a non-equilibrium state in non-aqueous media. The same was not observed for the PDMS fibre.
\end{abstract}

(C) 2008 Elsevier B.V. All rights reserved.

\section{Introduction}

In the overall quality of olive oil, the aroma plays an important role in directing consumer preference. Some components present in low concentration, contribute to the pleasant aroma note in olive oils, but when they are present in higher concentrations their contribution seems to be negative [1]. So it is important to determine, at least, the relative amounts of the aroma components of olive oil.

Compared to several techniques of sample preparation for gas chromatographic (GC) analysis of aroma compounds, headspace solid phase microextraction (HS-SPME) shows some advantages such as solvent-free extraction, low sample volumes and low cost. SPME is an equilibrium method, which does not require exhaustive extraction of a volume of sample [2].

It is known that olive oil is a complex matrix, with a high content of natural volatile compounds that have differences, among other physicochemical properties, in volatility and polarity. These different compounds are expected to present different equilibrium times. As HS-SPME is a multiphase equilibrium process [3], the

\footnotetext{
* Corresponding author. Tel.: +351 212948351.

E-mail addresses: lailarib@yahoo.com (L.H. Ribeiro), afreitas@uevora.pt (A.M. Costa Freitas), mdr@dq.fct.unl.pt (M.D.R. Gomes da Silva).
}

maximum sensibility is obtained by allowing the analyte(s) to reach equilibrium. It is not practical to do so when equilibration times are excessively long. Ai [4] presented a mathematical model (Eq. (1)) to demonstrate that SPME quantification, in aqueous solution, using fibres coated with a polymeric liquid, is feasible before absorption equilibrium is reached, if the amount of analyte absorbed $(n)$ is proportional to the initial concentration in the sample matrix $\left(C_{0}\right)$ :

$\frac{n}{n^{\infty}}=\left[1-\exp \left(-a_{\mathrm{h}} t\right)\right]$

$n \infty$ represents the amount extracted at equilibrium and the parameter $a_{\mathrm{h}}$ is a measure of how fast partition equilibrium can be reached in the HS-SPME process. The parameter $a_{\mathrm{h}}$ is controlled by mass transfer coefficients, equilibrium constants and the physical dimensions of the sample matrix, headspace and the polymeric film. It has different magnitudes depending on the ratedetermining step of the mass transfer process: matrix/headspace and headspace/polymer, diffusion in the polymeric film and evaporation from the matrix phase as described by Ai [4,5].

However, in Eq. (1) the initial period of extraction is neglected. In fact, during the sampling process, when the equilibrium between sample and headspace is reached, it is disturbed by the introduction of the fibre needle into the headspace. This disturbance is not considered in the model described by Eq. (1). Moreover, in complex 
Table 1

Typical concentrations and odour characteristics of compounds identified as odorants in olive oil

\begin{tabular}{|c|c|c|c|}
\hline No. & Compound & Concentration in olive oil ( $\mu \mathrm{g} / \mathrm{kg})$ & Odour quality [6] \\
\hline 1 & 2-Ethylfuran & - & Powerful, sweet, ethereal, burnt odour, coffee taste on dilution \\
\hline 2 & Pentan-3-one & $153-1053[7]$ & - \\
\hline 3 & Pent-1-en-3-one & $\begin{array}{r}634[7] \\
40-300[8] \\
26[9]\end{array}$ & Pungent, mustard \\
\hline 4 & Hexanal & 169-6367 [7] & Fatty, green, grassy, powerful, penetrating \\
\hline 5 & 4-Methyl-pent-3-en-2-one & - & Unpleasant, pungent, vegetable, acrylic \\
\hline 6 & 2-Methylbutan-1-ol & $\begin{array}{r}2809[7] \\
230-10,260[8]\end{array}$ & - \\
\hline 7 & Methoxybenzene & - & Phenolic, gasoline, ethereal, anise \\
\hline 8 & Hexan-1-ol & $\begin{array}{l}685-50,200[7] \\
680-10,260[8]\end{array}$ & Herbaceous, woody, fragrant, mild, sweet, green \\
\hline 9 & cis-Hex-3-en-1-ol & $\begin{array}{r}252-8587[7] \\
460-870[8] \\
684[9]\end{array}$ & Fresh, green grass \\
\hline 10 & trans-Hex-2-en-1-ol & $1118-89,100[7]$ & Powerful, leafy, green, wine-like, fruity \\
\hline 11 & 2-Ethyl-hexan-1-ol & - & Mild, oily, sweet, slight rose \\
\hline 12 & trans,trans-Non-2,4-dienal & $49[9]$ & Strong, fatty, floral \\
\hline 13 & trans,trans-Dec-2,4-dienal & $127-918[9]$ & Powerful, fatty, citrus \\
\hline
\end{tabular}

matrices, such as olive oil, this disturbance is even more important, since more equilibria are now being influenced by fibre needle introduction. $\mathrm{Ai}$ [5] proposed a biexponential equation (Eq. (2)) that accounts for this fact:

$\frac{n}{n^{\infty}}=\alpha[1-\exp (-c t)]+\beta\left[1-\exp \left(-c_{1} t\right)\right]$

Hybrid parameters $\alpha, c, \beta$ and $c_{1}$ are defined as

$$
\begin{gathered}
\alpha=\frac{b_{1}}{c-c_{1}} ; \quad \beta=\frac{a_{1}}{c_{1}}-\frac{b_{1}}{c-c_{1}} ; \quad c=k+\frac{A_{\mathrm{f}} m_{\mathrm{f}} K_{\mathrm{fh}}}{V_{\mathrm{h}}} ; \quad c_{1} \frac{2 A_{\mathrm{f}} m_{\mathrm{f}}}{V_{\mathrm{f}}} ; \\
a_{1}=A_{\mathrm{f}} m_{\mathrm{f}} K_{\mathrm{fh}} a ; \quad b_{1}=2 A_{\mathrm{f}} m_{\mathrm{f}} K_{\mathrm{fh}} b ; \quad a=\frac{k K_{\mathrm{hs}} V_{\mathrm{h}}}{k V_{\mathrm{h}}+A_{\mathrm{f}} m_{\mathrm{f}} K_{\mathrm{fh}}} C_{0} ; \\
b=\frac{A_{\mathrm{f}} m_{\mathrm{f}} K_{\mathrm{fh}} K_{\mathrm{hs}}}{k V_{\mathrm{h}}+A_{\mathrm{f}} m_{\mathrm{f}} k_{\mathrm{fh}}} C_{0}
\end{gathered}
$$

where $A_{\mathrm{f}}$ is the surface area of the SPME polymer film; $m_{\mathrm{f}}$ is the mass transfer coefficient of the analyte in polymer film phase; $k$ is the evaporation rate constant; $V_{\mathrm{h}}$ and $V_{\mathrm{f}}$ are the volumes of the headspace and the coating, respectively; $K_{\mathrm{fh}}$ is the polymer/headspace distribution constant; $K_{\mathrm{hs}}$ is the headspace/matrix distribution constant. Since $\alpha$ and $\beta$ (in mol, accounting for the variation of the quantity of a particular compound present in the headspace when the equilibrium is disturbed) are directly proportional to $C_{0}$ then $n$ is directly proportional to $C_{0}$. This fact implies that quantitative determination can be performed in a nonequilibrium state.

Since both mathematical models (Eqs. (1) and (2)) describe an absorption process, poly(dimethylsiloxane) (PDMS) and poly(acrylate) (PA) fibres were chosen for the present study. The methyl groups of PDMS make this film relatively apolar, whereas PA is a more polar fibre due to the presence of carbonyl groups.

This work aims the application of the mathematical models to a non-aqueous matrix, in this case an oily matrix, such as olive oil. This type of matrices are a better solvent for the majority of the volatile components of olive oil. It is intended to demonstrate that an important and complex matrix such as olive oil can also be studied considering the estimation parameters calculated according to one or to both mathematical models studied. A SPME sampling method was developed procedure for reproducible qualitative and relative quantitative determination of aroma compounds using non-equilibrium extraction conditions. We intended to determine not only which model describes better the experimental data obtained with each of the fibres studied, but also which fibre is more efficient for non-equilibrium state extraction in a non-aqueous medium.

\section{Experimental}

\subsection{Standards}

The standard compounds, 2-ethylfuran, pentan-3-one, 4methyl-pent-3-en-2-one, pent-1-en-3-one, 2-methylbutan-1-ol, hexanal, methoxybenzene, hexan-1-ol, cis-hex-3-en-1-ol, transhex-2-en-1-ol, 2-ethyl-hexan-1-ol, trans,trans-non-2,4-dienal and trans,trans-dec-2,4-dienal were purchased from Aldrich (Deisenhofen, Germany). The internal standard (IS) used was nonan-2-ol also from Aldrich (Deisenhofen, Germany).

\subsection{Sample preparation and analysis}

Standard compounds were dissolved directly in refined olive oil. Four concentrations, $0.256 \mu \mathrm{L} / \mathrm{kg}, 2.56 \mu \mathrm{L} / \mathrm{kg}, 6.25 \mu \mathrm{L} / \mathrm{kg}$ and $400 \mu \mathrm{L} / \mathrm{kg}$ were used. Fifteen grams of olive oil with the dissolved standards were placed in a $22 \mathrm{~mL}$ vial and kept in a water-thermostatized bath at $37^{\circ} \mathrm{C}$ for $30 \mathrm{~min}$ before the HS-SPME extraction. The septum covering the vial was pierced with a SPME needle and the fibre was exposed to the olive oil headspace for $1 \mathrm{~min}, 5 \mathrm{~min}, 15 \mathrm{~min}, 30 \mathrm{~min}, 60 \mathrm{~min}, 90 \mathrm{~min}$ and $120 \mathrm{~min}$. During sampling, the oil phase was stirred with a magnetic stirrer at a constant and defined stirring rate. After sampling, the fibre was inserted manually into the GC injection port for $5 \mathrm{~min}$ and desorbed at $260^{\circ} \mathrm{C}$.

\subsection{SPME fibres and conditioning}

SPME device and fused silica fibres were purchased from Supelco Inc. (Bellefonte, Pennsylvania, USA). Poly(acrylate) (PA) and poly(dimethylsiloxane) (PDMS) SPME fibres with coating thicknesses of $85 \mu \mathrm{m}$ and $100 \mu \mathrm{m}$, respectively were used. Prior to use, the fibres were conditioned according to manufacturer instructions. 

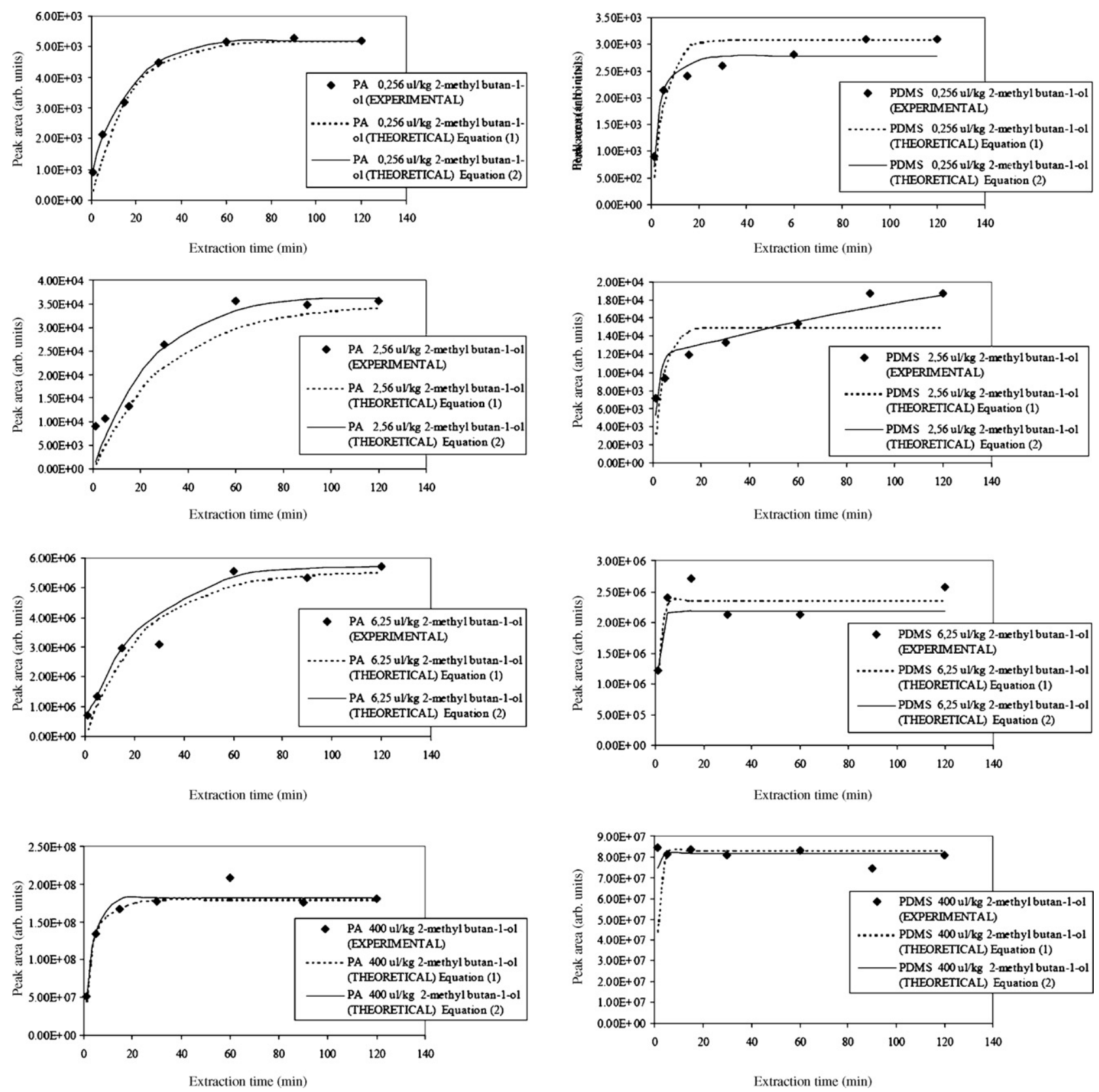

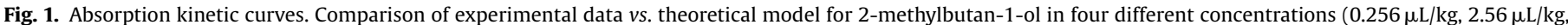
$6.25 \mu \mathrm{L} / \mathrm{kg}$ and $400 \mu \mathrm{L} / \mathrm{kg}$ ) at $37^{\circ} \mathrm{C}$ for the PA and the PDMS fibres.

\subsection{Equipment}

GC analyses were performed using a GC-Trace Thermo Quest Instruments. For GC analyses, a fused silica DB-Wax column (J\&W Scientific, Folsom, USA), $60 \mathrm{~m} \times 0.25 \mathrm{~mm}$ i.d. and $1.0 \mu \mathrm{m}$ film thickness was used. The oven temperature program was as follow: $50^{\circ} \mathrm{C}$ (5 min), $2^{\circ} \mathrm{C} \mathrm{min}^{-1}$ to $210^{\circ} \mathrm{C}(10 \mathrm{~min})$. Hydrogen was used as the carrier gas at $100 \mathrm{kPa}$; the injector temperature and the split flow were set at $260^{\circ} \mathrm{C}$ and $30 \mathrm{~mL} \mathrm{~min}^{-1}$, respectively, after a splitless time of $1 \mathrm{~min}$.

\subsection{Data processing}

The relative area data of each compound were obtained from the collected chromatograms. The adjustment of the extraction data (for the HS-SPME studies) to the theoretical models described above as Eqs. (1) and (2), was performed through an estimation method by non-linear regression method.

Data were analysed using STATISTICA 6.0 software (StatSoft Inc., Version 6.0, Tulsa, USA). Non-linear estimation user-specified regression was used. The estimation method was the quasi-Newton with a maximum number of iterations of 100 . The convergence criterion was set to 0.0001 and the loss function was equal to (observed data - predicted values) ${ }^{2}$.

\section{Results and discussion}

The volatile compounds chosen for method evaluation were studied with two different SPME fibre coatings and with four different initial concentrations that are comparable to the con- 
Table 2

Parameter $a_{\mathrm{h}}$ values calculated according to Eq. (1) for selected compounds in PA fibre at $37^{\circ} \mathrm{C}$ using different initial concentrations

\begin{tabular}{|c|c|c|c|c|c|}
\hline Compound & $C_{0}(\mu \mathrm{L} / \mathrm{kg})$ & Parameter, $a_{h}$ (estimated) & Correlation coefficient & Explained variance (\%) & Final loss \\
\hline \multicolumn{6}{|c|}{ PA Eq. (1) model: $n / n^{\infty}=1-\exp \left(-a_{\mathrm{h}} t\right)$} \\
\hline \multirow[t]{2}{*}{ 2-Ethylfuran } & 0.256 & 0.2003 & 0.9587 & 90.679 & 0.01718 \\
\hline & 2.56 & 0.1046 & 0.9259 & 85.729 & 0.05610 \\
\hline \multirow[t]{2}{*}{ Pent-3-one } & 0.256 & 0.0213 & 0.9687 & 93.819 & 0.01632 \\
\hline & 2.56 & 0.0748 & 0.9944 & 99.548 & 0.00683 \\
\hline \multirow[t]{2}{*}{ Pent-1-en-3-one } & 0.256 & 0.0276 & 0.9574 & 90.817 & 0.01521 \\
\hline & 2.56 & 0.0504 & 0.9908 & 98.171 & 0.00635 \\
\hline \multirow[t]{2}{*}{ Hexanal } & 0.256 & 0.0947 & 0.9511 & 90.459 & 0.01633 \\
\hline & 2.56 & 0.1201 & 0.9685 & 93.927 & 0.02447 \\
\hline \multirow[t]{4}{*}{ 4-Methyl-pent-3-en-2-one } & 0.256 & 0.0610 & 0.9118 & 83.134 & 0.03176 \\
\hline & 2.56 & 0.0613 & 0.9794 & 94.726 & 0.02241 \\
\hline & 6.25 & 0.0665 & 0.9601 & 93.717 & 0.05509 \\
\hline & 400 & 0.1573 & 0.9746 & 94.958 & 0.02166 \\
\hline \multirow[t]{4}{*}{ 2-Methylbutan-1-ol } & 0.256 & 0.0620 & 0.9685 & 93.797 & 0.01431 \\
\hline & 2.56 & 0.0317 & 0.9221 & 85.027 & 0.05140 \\
\hline & 6.25 & 0.0414 & 0.9706 & 94.801 & 0.04762 \\
\hline & 400 & 0.2853 & 0.9681 & 93.877 & 0.03018 \\
\hline \multirow[t]{4}{*}{ Methoxybenzene } & 0.256 & 0.0094 & 0.9537 & 90.956 & 0.01864 \\
\hline & 2.56 & 0.0411 & 0.9726 & 94.882 & 0.02659 \\
\hline & 6.25 & 0.0912 & 0.9656 & 93.997 & 0.02575 \\
\hline & 400 & 0.1900 & 0.9505 & 90.418 & 0.05919 \\
\hline \multirow[t]{4}{*}{ Hexan-1-ol } & 0.256 & 0.0639 & 0.9790 & 95.852 & 0.00991 \\
\hline & 2.56 & 0.0689 & 0.9712 & 94.791 & 0.02348 \\
\hline & 6.25 & 0.0638 & 0.9683 & 93.918 & 0.01927 \\
\hline & 400 & 0.5292 & 0.9679 & 93.874 & 0.01956 \\
\hline \multirow[t]{4}{*}{ cis-Hex-3-en-1-ol } & 0.256 & 0.0519 & 0.9616 & 92.461 & 0.01810 \\
\hline & 2.56 & 0.0721 & 0.9668 & 93.889 & 0.01992 \\
\hline & 6.25 & 0.0754 & 0.9999 & 99.999 & 0.19901 \\
\hline & 400 & 0.3774 & 0.9621 & 93.357 & 0.05625 \\
\hline \multirow[t]{4}{*}{ trans-Hex-2-en-1-ol } & 0.256 & 0.0348 & 0.9575 & 91.682 & 0.04388 \\
\hline & 2.56 & 0.0710 & 0.9698 & 93.969 & 0.01981 \\
\hline & 6.25 & 0.0789 & 0.9729 & 94.816 & 0.02480 \\
\hline & 400 & 0.3495 & 0.9957 & 99.655 & 0.00842 \\
\hline \multirow[t]{4}{*}{ 2-Ethyl-hexan-1-ol } & 0.256 & 0.0262 & 0.9736 & 94.797 & 0.02069 \\
\hline & 2.56 & 0.0399 & 0.9821 & 96.613 & 0.00227 \\
\hline & 6.25 & 0.0415 & 0.9973 & 99.677 & 0.00445 \\
\hline & 400 & 0.2235 & 0.9912 & 99.204 & 0.00640 \\
\hline \multirow[t]{2}{*}{ trans,trans-Non-2,4-dienal } & 0.256 & 0.0497 & 0.9338 & 87.206 & 0.02590 \\
\hline & 2.56 & 0.0270 & 0.9535 & 90.671 & 0.01638 \\
\hline \multirow[t]{4}{*}{ trans,trans-Dec-2,4-dienal } & 0.256 & 0.0814 & 0.9596 & 91.727 & 0.04991 \\
\hline & 2.56 & 0.0354 & 0.9582 & 91.699 & 0.05290 \\
\hline & 6.25 & 0.0377 & 0.9758 & 94.817 & 0.02538 \\
\hline & 400 & 0.0682 & 0.9649 & 93.669 & 0.05166 \\
\hline
\end{tabular}

centrations found in olive oils. Their diversified chemical nature and different odorific notes [6] determined their choice. All of these compounds were previously detected in olive oil [7-10]. Table 1 presents the compounds used in this study and it also indicates the concentrations which have been previously measured in olive oil samples and the respective odour perceptions [6]. The analytes chosen intend to represent the broad chemical functionalities of the compounds present in olive oils. An internal standard was used in order to control the retention time.

Prior to the analyses, a temperature study was performed for a time periods from $1 \mathrm{~min}$ to $120 \mathrm{~min}$ in order to establish the optimal work temperature of the extraction procedure [11]. Three temperatures were studied: $25^{\circ} \mathrm{C}, 37^{\circ} \mathrm{C}$ and $40^{\circ} \mathrm{C}$. At $37^{\circ} \mathrm{C}$ and $40^{\circ} \mathrm{C}$ the largest amount of compounds was extracted with both fibres (results not shown) [11]. Another concern was to choose a temperature as close as possible that at which the human olfative systems perceives volatile emissions on one hand, and on the other hand to avoid compound degradation that might produce unwanted artefacts. For these reasons $37^{\circ} \mathrm{C}$ was chosen as the sampling temperature.

The standard compounds were extracted at six or seven different periods of time and the results of each area $v s$. extraction time were determined. As an example, the absorption curves for 2methylbutan-1-ol for the concentrations $0.256 \mu \mathrm{L} / \mathrm{kg}, 2.56 \mu \mathrm{L} / \mathrm{kg}$, $6.25 \mu \mathrm{L} / \mathrm{kg}$ and $400 \mu \mathrm{L} / \mathrm{kg}$ are shown in Fig. 1. A sigmoidal-shape curve can be observed which does not depend on the initial concentration, the nature of the coating fibres or the mathematical model 
Table 3

Parameter $a_{\mathrm{h}}$ values calculated according to Eq. (1) for selected compounds in PDMS at $37^{\circ} \mathrm{C}$ using different initial concentrations

\begin{tabular}{|c|c|c|c|c|c|}
\hline Compound & $C_{0}(\mu \mathrm{L} / \mathrm{kg})$ & Parameter, $a_{\mathrm{h}}$ (estimated) & Correlation coefficient & Explained variance (\%) & Final loss \\
\hline \multicolumn{6}{|c|}{ PDMS Eq. (1) model: $n / n^{\infty}=1-\exp \left(-a_{\mathrm{h}} t\right)$} \\
\hline \multirow[t]{2}{*}{ 2-Ethylfuran } & 0.256 & 0.3127 & 0.9981 & 99.778 & 0.00501 \\
\hline & 2.56 & 0.0337 & 0.9698 & 94.051 & 0.02642 \\
\hline \multirow[t]{2}{*}{ Pent-3-one } & 0.256 & 0.0427 & 0.9912 & 99.101 & 0.00958 \\
\hline & 2.56 & 0.0411 & 0.9833 & 96.687 & 0.00184 \\
\hline \multirow[t]{2}{*}{ Pent-1-en-3-one } & 0.256 & 0.0376 & 0.9823 & 96.489 & 0.01829 \\
\hline & 2.56 & 0.2242 & 0.9962 & 99.607 & 0.00221 \\
\hline \multirow[t]{2}{*}{ Hexanal } & 0.256 & 0.0857 & 0.9841 & 96.915 & 0.00231 \\
\hline & 2.56 & 0.0835 & 0.9944 & 99.366 & 0.00992 \\
\hline \multirow[t]{4}{*}{ 4-Methyl-pent-3-en-2-one } & 0.256 & 0.0245 & 0.9833 & 96.687 & 0.00180 \\
\hline & 2.56 & 0.2629 & 0.9951 & 99.566 & 0.00734 \\
\hline & 6.25 & 0.9898 & 0.9764 & 94.856 & 0.02873 \\
\hline & 400 & 0.5240 & 0.9993 & 99.877 & 0.00157 \\
\hline \multirow[t]{4}{*}{ 2-Methylbutan-1-ol } & 0.256 & 0.1886 & 0.9983 & 99.772 & 0.00441 \\
\hline & 2.56 & 0.2419 & 0.9961 & 99.714 & 0.00710 \\
\hline & 6.25 & 0.7468 & 0.9997 & 99.897 & 0.00122 \\
\hline & 400 & 0.7667 & 0.9999 & 99.999 & 0.01144 \\
\hline \multirow[t]{4}{*}{ Methoxybenzene } & 0.256 & 0.0315 & 0.9861 & 96.799 & 0.00312 \\
\hline & 2.56 & 0.2799 & 0.9945 & 99.423 & 0.00980 \\
\hline & 6.25 & 0.3732 & 0.9994 & 99.818 & 0.00411 \\
\hline & 400 & 0.3483 & 0.9798 & 94.901 & 0.02391 \\
\hline \multirow[t]{4}{*}{ Hexan-1-ol } & 0.256 & 0.0289 & 0.9891 & 96.988 & 0.00673 \\
\hline & 2.56 & 0.3106 & 0.9559 & 91.667 & 0.04535 \\
\hline & 6.25 & 0.7631 & 0.9845 & 96.918 & 0.00522 \\
\hline & 400 & 0.7316 & 0.9584 & 91.701 & 0.03990 \\
\hline \multirow[t]{4}{*}{ cis-Hex-3-en-1-ol } & 0.256 & 0.0260 & 0.9978 & 99.267 & 0.00371 \\
\hline & 2.56 & 0.5509 & 0.9999 & 99.999 & 0.05426 \\
\hline & 6.25 & 0.9401 & 0.9992 & 99.879 & 0.00248 \\
\hline & 400 & 0.5509 & 0.9751 & 94.841 & 0.02866 \\
\hline \multirow[t]{4}{*}{ trans-Hex-2-en-1-ol } & 0.256 & 0.0322 & 0.9833 & 96.855 & 0.00719 \\
\hline & 2.56 & 0.9185 & 0.9989 & 99.998 & 0.00422 \\
\hline & 6.25 & 0.9193 & 0.9996 & 99.879 & 0.00310 \\
\hline & 400 & 0.7284 & 0.9581 & 91.655 & 0.04901 \\
\hline \multirow[t]{4}{*}{ 2-Ethyl-hexan-1-ol } & 0.256 & 0.0971 & 0.9959 & 99.864 & 0.00371 \\
\hline & 2.56 & 0.3625 & 0.9999 & 99.999 & 0.06117 \\
\hline & 6.25 & 0.3906 & 0.9776 & 94.966 & 0.01136 \\
\hline & 400 & 0.4728 & 0.9859 & 96.997 & 0.00281 \\
\hline \multirow[t]{2}{*}{ trans,trans-Non-2,4-dienal } & 0.256 & 0.0647 & 0.9590 & 91.675 & 0.04547 \\
\hline & 2.56 & 0.3603 & 0.9999 & 99.999 & 0.00131 \\
\hline \multirow[t]{4}{*}{ trans,trans-Dec-2,4-dienal } & 0.256 & 0.0542 & 0.9813 & 96.289 & 0.01512 \\
\hline & 2.56 & 0.1133 & 0.9966 & 99.274 & 0.00282 \\
\hline & 6.25 & 0.4030 & 0.9755 & 94.899 & 0.02711 \\
\hline & 400 & 0.2586 & 0.9991 & 99.884 & 0.00109 \\
\hline
\end{tabular}

applied. The adjusted curves according to Eqs. (1) and (2) of the model of Ai [4] are shown in the graphs of Fig. 1, for 2-methylbutan1-ol for both fibres at the concentrations studied. Here the points are raw experimental data and the lines represent the result of the application of the two equations to the experimental data.

The parameters $a_{\mathrm{h}}$ from Eq. (1) and $\alpha, c, \beta$, and $c_{1}$ from Eq. (2) for all the compounds studied, in PDMS and PA coating fibres, are obtained through exponential regression. Tables 2 and 3 show the values for the $a_{\mathrm{h}}$ parameter, correlation coefficient, explained variance and the loss function for the curves fitted with Eq. (1). The parameters of Eq. (2), $\alpha, c, \beta$, and $c_{1}$ are listed in Tables 4 and 5 , as well as the correlation coefficients, explained variance and the loss function for all fitted curves.
For the selected compounds, the experimental data appears to fit poorly, as expected, to the theoretical model given by Eq. (1).

All the curves could however be satisfactorily described by Eq (2) and confirm the relevance of the initial period of extraction for the absorption of the olive oil volatiles mainly in PA fibre. Similar results were reported previously by Matich et al. [12] who observed that a two-exponential equation, rather a one-exponential equation, described the experimental data for apple volatiles extracted by SPME.

The values for the $a_{\mathrm{h}}$ parameter for the four different initial concentrations studied are slightly dependent on the initial concentration, as expected [13], especially for the PA fibre.

In Fig. 1 it can be easily perceived how fast the partition equilibrium (between the headspace/polymer interfaces) can be reached, 
Table 4

Parameters $\alpha, c, \beta, c_{1}$ values calculated according to Eq. (2) for selected compounds in PA fibre at $37^{\circ} \mathrm{C}$ using different initial

\begin{tabular}{|c|c|c|c|c|c|c|c|c|}
\hline \multirow[t]{2}{*}{ Compound } & \multirow[t]{2}{*}{$C_{0}(\mu \mathrm{L} / \mathrm{kg})$} & \multicolumn{4}{|c|}{ Estimated parameters } & \multirow[t]{2}{*}{ Correlation coefficient } & \multirow[t]{2}{*}{ Explained variance (\%) } & \multirow[t]{2}{*}{ Final loss } \\
\hline & & $\alpha$ & $c$ & $\beta$ & $c_{1}$ & & & \\
\hline \multicolumn{9}{|c|}{ PA Eq. (2) model: $n / n^{\infty}=\alpha[1-\exp (-c t)]+\beta\left[1-\exp \left(-c_{1} t\right)\right]$} \\
\hline \multirow{2}{*}{ 2-Ethylfuran } & 0.256 & 0.8998 & 0.0085 & 0.5753 & 0.4331 & 0.9996 & 99.95 & 0.00092 \\
\hline & 2.56 & 0.5346 & 0.0894 & 0.5346 & 0.0894 & 0.9948 & 99.835 & 0.00441 \\
\hline \multirow[t]{2}{*}{ Pent-3-one } & 0.256 & 0.6162 & 0.0232 & 0.6163 & 0.0232 & 0.9473 & 89.745 & 0.06236 \\
\hline & 2.56 & 0.8777 & 0.0180 & 0.4186 & 0.9755 & 0.9987 & 97.861 & 0.00111 \\
\hline \multirow[t]{2}{*}{ Pent-1-en-3-one } & 0.256 & 0.9766 & 0.0102 & 0.8245 & 0.0100 & 0.9913 & 99.114 & 0.00779 \\
\hline & 2.56 & 0.8133 & 0.0988 & 0.9798 & 0.0054 & 0.9999 & 99.997 & 0.00011 \\
\hline \multirow[t]{2}{*}{ Hexanal } & 0.256 & 0.6407 & 0.9699 & 0.9778 & 0.0052 & 0.9733 & 95.644 & 0.02711 \\
\hline & 2.56 & 0.7769 & 0.0953 & 0.8766 & 0.0091 & 0.9998 & 99.960 & 0.00014 \\
\hline \multirow[t]{4}{*}{ 4-Methyl-pent-3-en-2-one } & 0.256 & 0.9888 & 0.0091 & 0.4657 & 0.9589 & 0.9981 & 99.650 & 0.00208 \\
\hline & 2.56 & 0.6044 & 0.0237 & 0.6044 & 0.0237 & 0.9857 & 97.168 & 0.01673 \\
\hline & 6.25 & 0.6573 & 0.0332 & 0.37822 & 0.2617 & 0.97509 & 95.081 & 0.03474 \\
\hline & 400 & 0.7798 & 0.0081 & 0.8712 & 0.3866 & 0.9878 & 97.921 & 0.02067 \\
\hline \multirow[t]{4}{*}{ 2-Methylbutan-1-ol } & 0.256 & 0.9068 & 0.0401 & 0.2331 & 0.9918 & 0.9988 & 99.630 & 0.00148 \\
\hline & 2.56 & 0.5297 & 0.0396 & 0.5297 & 0.0396 & 0.9693 & 93.944 & 0.02704 \\
\hline & 6.25 & 0.2437 & 0.8876 & 0.9552 & 0.0476 & 0.9982 & 99.236 & 0.00283 \\
\hline & 400 & 0.5064 & 0.2760 & 0.5064 & 0.2760 & 0.9689 & 93.883 & 0.02942 \\
\hline \multirow[t]{4}{*}{ Methoxybenzene } & 0.256 & 0.3101 & 0.7898 & 0.7748 & 0.0122 & 0.9997 & 99.944 & 0.00023 \\
\hline & 2.56 & 0.5842 & 0.0307 & 0.5842 & 0.0307 & 0.9439 & 89.094 & 0.06708 \\
\hline & 6.25 & 0.4158 & 0.9661 & 0.8803 & 0.0730 & 0.9794 & 95.918 & 0.03102 \\
\hline & 400 & 0.4758 & 0.2163 & 0.4758 & 0.2163 & 0.9932 & 98.653 & 0.00604 \\
\hline \multirow[t]{4}{*}{ Hexan-1-ol } & 0.256 & 0.4623 & 0.0748 & 0.4623 & 0.0748 & 0.9606 & 92.284 & 0.01966 \\
\hline & 2.56 & 0.3484 & 0.5082 & 0.8578 & 0.0296 & 0.9995 & 99.907 & 0.00033 \\
\hline & 6.25 & 0.2716 & 0.9908 & 0.8527 & 0.0677 & 0.9962 & 99.559 & 0.00142 \\
\hline & 400 & 0.4922 & 0.5519 & 0.4922 & 0.5519 & 0.9955 & 99.738 & 0.00221 \\
\hline \multirow[t]{4}{*}{ cis-Hex-3-en-1-ol } & 0.256 & 0.8938 & 0.0289 & 0.2878 & 0.7679 & 0.9913 & 98.266 & 0.00614 \\
\hline & 2.56 & 0.2259 & 0.9986 & 0.8984 & 0.0311 & 0.9766 & 94.078 & 0.01948 \\
\hline & 6.25 & 0.5018 & 0.0747 & 0.5018 & 0.0747 & 0.8730 & 76.216 & 0.19902 \\
\hline & 400 & 0.5020 & 0.3736 & 0.5020 & 0.3736 & 0.9317 & 86.800 & 0.05527 \\
\hline \multirow[t]{4}{*}{ trans-Hex-2-en-1-ol } & 0.256 & 0.5822 & 0.0257 & 0.5822 & 0.0257 & 0.9700 & 94.089 & 0.03119 \\
\hline & 2.56 & 0.1267 & 0.7637 & 0.9931 & 0.0310 & 0.9709 & 94.256 & 0.02623 \\
\hline & 6.25 & 0.5034 & 0.0776 & 0.5034 & 0.0776 & 0.9001 & 81.002 & 0.16214 \\
\hline & 400 & 0.4911 & 0.3662 & 0.4911 & 0.3662 & 0.9135 & 83.445 & 0.06991 \\
\hline \multirow[t]{4}{*}{ 2-Ethyl-hexan-1-ol } & 0.256 & 0.6386 & 0.0195 & 0.6389 & 0.0195 & 0.9736 & 94.788 & 0.03154 \\
\hline & 2.56 & 0.8587 & 0.5337 & 0.8779 & 0.0034 & 0.9997 & 99.913 & 0.00023 \\
\hline & 6.25 & 0.1956 & 0.9898 & 0.8761 & 0.0397 & 0.9475 & 89.775 & 0.06889 \\
\hline & 400 & 0.4985 & 0.2256 & 0.4985 & 0.2256 & 0.9328 & 87.001 & 0.07414 \\
\hline \multirow[t]{2}{*}{ trans,trans-Non-2,4-dienal } & 0.256 & 0.7998 & 0.0209 & 0.2311 & 0.8667 & 0.9953 & 98.45 & 0.00563 \\
\hline & 2.56 & 0.3798 & 0.0244 & 0.3798 & 0.0244 & 0.9994 & 99.880 & 0.00032 \\
\hline \multirow[t]{4}{*}{ trans,trans-Dec-2,4-dienal } & 0.256 & 0.5858 & 0.0129 & 0.6200 & 0.2060 & 0.9621 & 92.566 & 0.01750 \\
\hline & 2.56 & 0.6417 & 0.0220 & 0.6417 & 0.0220 & 0.9847 & 96.954 & 0.01949 \\
\hline & 6.25 & 0.6997 & 0.0344 & 0.6997 & 0.0344 & 0.9961 & 98.54 & 0.00314 \\
\hline & 400 & 0.7733 & 0.0586 & 0.1872 & 0.3585 & 0.9736 & 94.794 & 0.03901 \\
\hline
\end{tabular}

for a given compound. In this figure, the ordinate represents the fibre uptake normalized to the equilibrium value. Compared to olive oil headspace/PA interface partition, the parameter $a_{\mathrm{h}}$ at the olive oil headspace/PDMS interface is higher, which means that in the PDMS fibre the partition equilibrium is reached sooner. This is in agreement with the fact that on the PA fibre diffusion coefficients are lower in comparison with the PDMS fibre [14]. Longer extraction times with the PA coating fibre for volatile analytes in the headspace is an expected result. The selection of the fibre that offers the best reproducible results for quantitative purposes, should depend not only on the amount extracted, but also on some other physical/chemical properties such as mass transfer coefficients, equilibrium constants, among others, in order to achieve a linear range behaviour in a non-equilibrium state $[4,15]$. This work demonstrates that PDMS fibres present for all the compounds studied, lower equilibration times when compared to PA fibres, although PA fibres present a better absorption capacity for compounds with a wide range of functionalities. The initial concentration is crucial for the time profile and the achievement of equilibrium in both fibres. Generally the $a_{\mathrm{h}}$ parameter is higher when the initial concentration is higher, indicating that equilibrium is reached quicker in that situation for both fibres. Since Eq. (1) does not fit as well to the experimental data when compared to Eq. (2), one cannot have any information about the proportionality between the initial concentration and amount extracted. So the biexponential equation (2) was applied to the data. 
Table 5

Parameters $\alpha, c, \beta, c_{1}$ values calculated according to Eq. (2) for selected compounds in PDMS fibre at $37^{\circ} \mathrm{C}$ using different initial concentrations

\begin{tabular}{|c|c|c|c|c|c|c|c|c|}
\hline \multirow[t]{2}{*}{ Compound } & \multirow[t]{2}{*}{$C_{0}(\mu \mathrm{L} / \mathrm{kg})$} & \multicolumn{4}{|c|}{ Estimated parameters } & \multirow[t]{2}{*}{ Correlation coefficient } & \multirow[t]{2}{*}{ Explained variance (\%) } & \multirow[t]{2}{*}{ Final loss } \\
\hline & & $\alpha$ & $c$ & $\beta$ & $c_{1}$ & & & \\
\hline \multicolumn{9}{|c|}{ PDMS Eq. (2) model: $n / n^{\infty}=\alpha[1-\exp (-c t)]+\beta\left[1-\exp \left(-c_{1} t\right)\right]$} \\
\hline \multirow[t]{2}{*}{ 2-Ethylfuran } & 0.256 & 0.6107 & 0.3265 & 0.6107 & 0.3265 & 0.9520 & 91.752 & 0.00567 \\
\hline & 2.56 & 0.4215 & 0.7108 & 0.4215 & 0.7108 & 0.9894 & 97.883 & 0.00941 \\
\hline \multirow[t]{2}{*}{ Pent-3-one } & 0.256 & 0.8939 & 0.0078 & 0.5624 & 0.9778 & 0.9654 & 93.204 & 0.01904 \\
\hline & 2.56 & 0.5384 & 0.0353 & 0.5384 & 0.0353 & 0.9879 & 97.597 & 0.01333 \\
\hline \multirow[t]{2}{*}{ Pent-1-en-3-one } & 0.256 & 0.5780 & 0.0279 & 0.5780 & 0.0279 & 0.9950 & 99.003 & 0.00523 \\
\hline & 2.56 & 0.4510 & 0.3209 & 0.4510 & 0.3209 & 0.9677 & 93.312 & 0.02235 \\
\hline \multirow[t]{2}{*}{ Hexanal } & 0.256 & 0.5975 & 0.0239 & 0.5092 & 0.3247 & 0.9992 & 99.839 & 0.00032 \\
\hline & 2.56 & 0.4759 & 0.6125 & 0.5894 & 0.0246 & 0.9999 & 99.991 & 0.00001 \\
\hline \multirow[t]{4}{*}{ 4-Methyl-pent-3-en-2-one } & 0.256 & 0.3514 & 0.9886 & 0.9599 & 0.0011 & 0.8919 & 79.558 & 0.07828 \\
\hline & 2.56 & 0.4410 & 0.3978 & 0.4410 & 0.3978 & 0.9816 & 97.427 & 0.01521 \\
\hline & 6.25 & 0.6602 & 0.9898 & 0.6602 & 0.9898 & 0.9368 & 87.762 & 0.00970 \\
\hline & 400 & 0.4958 & 0.5474 & 0.4958 & 0.5474 & 0.7958 & 63.324 & 0.00191 \\
\hline \multirow[t]{4}{*}{ 2-Methylbutan-1-ol } & 0.256 & 0.4486 & 0.2906 & 0.4486 & 0.2906 & 0.9861 & 97.548 & 0.01414 \\
\hline & 2.56 & 0.9998 & 0.0051 & 0.7756 & 0.5926 & 0.9916 & 98.088 & 0.00619 \\
\hline & 6.25 & 0.4651 & 0.8052 & 0.4651 & 0.8052 & 0.8776 & 77.019 & 0.04126 \\
\hline & 400 & 0.4929 & 0.9798 & 0.4929 & 0.9798 & 0.9265 & 85.836 & 0.00101 \\
\hline \multirow[t]{4}{*}{ Methoxybenzene } & 0.256 & 0.6215 & 0.9869 & 0.9994 & 0.0013 & 0.9793 & 95.907 & 0.01221 \\
\hline & 2.56 & 0.4605 & 0.3680 & 0.4605 & 0.3680 & 0.9877 & 97.568 & 0.00977 \\
\hline & 6.25 & 0.4930 & 0.3893 & 0.4930 & 0.3894 & 0.9216 & 84.931 & 0.05279 \\
\hline & 400 & 0.4825 & 0.3943 & 0.4825 & 0.3943 & 0.9868 & 97.614 & 0.01247 \\
\hline \multirow[t]{4}{*}{ Hexan-1-ol } & 0.256 & 0.9899 & 0.0021 & 0.3315 & 0.92357 & 0.9756 & 95.046 & 0.03832 \\
\hline & 2.56 & 0.4984 & 0.3250 & 0.4984 & 0.3250 & 0.9884 & 97.721 & 0.00872 \\
\hline & 6.25 & 0.5294 & 0.6566 & 0.5294 & 0.6566 & 0.9155 & 83.819 & 0.04517 \\
\hline & 400 & 0.5813 & 0.9788 & 0.5813 & 0.9788 & 0.7363 & 54.212 & 0.02446 \\
\hline \multirow[t]{4}{*}{ cis-Hex-3-en-1-ol } & 0.256 & 0.8898 & 0.0024 & 0.4353 & 0.7689 & 0.9231 & 85.664 & 0.06423 \\
\hline & 2.56 & 0.5245 & 0.4418 & 0.5245 & 0.4418 & 0.9927 & 98.058 & 0.00781 \\
\hline & 6.25 & 0.4945 & 0.9355 & 0.4945 & 0.9355 & 0.9236 & 85.311 & 0.02124 \\
\hline & 400 & 0.4779 & 0.7546 & 0.4779 & 0.7546 & 0.9832 & 97.578 & 0.01247 \\
\hline \multirow[t]{4}{*}{ trans-Hex-2-en-1-ol } & 0.256 & 0.9899 & 0.0032 & 0.3973 & 0.3177 & 0.9616 & 92.461 & 0.02358 \\
\hline & 2.56 & 0.5734 & 0.3859 & 0.5734 & 0.3859 & 0.9931 & 98.107 & 0.00577 \\
\hline & 6.25 & 0.4736 & 0.9656 & 0.4736 & 0.9656 & 0.8242 & 67.924 & 0.04853 \\
\hline & 400 & 0.4904 & 0.7967 & 0.4904 & 0.7967 & 0.9865 & 97.547 & 0.01351 \\
\hline \multirow[t]{4}{*}{ 2-Ethyl-hexan-1-ol } & 0.256 & 0.4784 & 0.1109 & 0.4784 & 0.1109 & 0.9446 & 89.233 & 0.01924 \\
\hline & 2.56 & 0.5413 & 0.2835 & 0.5413 & 0.2835 & 0.9922 & 98.098 & 0.00712 \\
\hline & 6.25 & 0.4818 & 0.4189 & 0.4818 & 0.4189 & 0.95464 & 91.133 & 0.03867 \\
\hline & 400 & 0.5934 & 0.4728 & 0.5934 & 0.4728 & 0.9921 & 98.203 & 0.00439 \\
\hline \multirow[t]{2}{*}{ trans,trans-Non-2,4-dienal } & 0.256 & 0.6485 & 0.3395 & 0.8898 & 0.0041 & 0.9668 & 92.742 & 0.01942 \\
\hline & 2.56 & 0.5277 & 0.3203 & 0.5277 & 0.3203 & 0.9918 & 98.179 & 0.00455 \\
\hline \multirow[t]{4}{*}{ trans,trans-Dec-2,4-dienal } & 0.256 & 0.5156 & 0.0508 & 0.5156 & 0.0508 & 0.9864 & 97.311 & 0.01391 \\
\hline & 2.56 & 0.4643 & 0.1482 & 0.4643 & 0.1482 & 0.9878 & 97.598 & 0.01033 \\
\hline & 6.25 & 0.5219 & 0.3641 & 0.5219 & 0.3641 & 0.9557 & 91.329 & 0.04179 \\
\hline & 400 & 0.4911 & 0.3165 & 0.4911 & 0.3165 & 0.9869 & 97.687 & 0.00733 \\
\hline
\end{tabular}

We found that absorption of olive oil volatiles onto PDMS and PA SPME fibres follow, in a good approximation, the general kinetic equation (2), especially in the case of the PA fibre. In the PDMS fibre the experimental data does not fit well to Eq. (2), suggesting that linearity between initial concentration and extracted amount is not achieved. Thus relative quantification is not possible with the PDMS fibre in a non-equilibrium state. With the PA fibre, a good fit was achieved with Eq. (2), which indicates that there is a linear relationship between the amount of analyte extracted $(n)$, from olive oil headspace, and its initial concentration in the sample matrix $\left(C_{0}\right)$ as a function of sampling time $(t)$. This equation considers the equilibrium disturbance due to fibre introduction into the headspace of the sample, the equilibrium reposition and the variation of the compound concentrations in the sample headspace, which occurs between the disturbance and reposition time periods. For compounds that present $c$ values equal to $c_{1}$ values (presenting both adjustment parameters in Eq. (2), which measure how fast the equilibrium is reached in HS-SPME) $\left(c-c_{1}\right)=0$, meaning that the equilibrium is not disturbed, or the equilibrium reposition takes place immediately. For these compounds it is also verified that for $\alpha$ and $\beta$, which measure the variation of the concentration of a particular compound presented in the headspace, due to the equilibrium disturbance, $|\alpha|=|\beta|$. Hence the $a_{\mathrm{h}}=0$ and the parameter $c$ in Eq. (2) is equal to $a_{\mathrm{h}}$ in Eq. (1). 
The PA fibre allows, for the compounds studied, a successful relative quantification at a non-equilibrium state in non-aqueous media. Consequently, in non-aqueous media studies must be conducted to determine which compounds have similar behaviour and only those compounds can be quantified in a non-equilibrium situation with the PA fibre. For all the others, and for quantitative purposes, equilibrium should be reached.

\section{Conclusion}

The HS-SPME sample preparation technique coupled with GC analysis is well suited for qualitative and relative quantitative analysis of aroma compounds in olive oil. The amount $(n)$ of analyte extracted, from olive oil headspace, might have a linear proportional relation with its initial concentration in the sample matrix $\left(C_{0}\right)$ as a function of sampling time $(t)$, which can be an advantage in the case of routine use. When a given compound in a given sample matrix exhibits this property, quantification can be achieved at nonequilibrium state, which reduces analysis time considerably. In all the other situations equilibrium should be reached for quantitative purposes.

Although it was observed that apolar PDMS-coated fibre is capable of extracting faster the olive oil aroma compounds for routine purposes in comparison with the PA fibre, since equilibrium is reached more quickly, the experimental data obtained with the PDMS fibre did not adjust to both mathematical models used. This indicates that linear proportionality between the initial concentration and amount extracted was not achieved, which does not allow relative quantification in non-equilibrium situations. On the other hand the PA fibre was found to be the adequate fibre to perform relative quantification of aroma compounds in a non-equilibrium state in a non-aqueous sample like olive oil.

\section{Acknowledgments}

The authors wish to thank Prof. José Gouveia from Instituto Superior de Agronomia for the gift of refined olive oil. The work developed was partially sponsored by the program PRAXIS contract Nr. PRAXIS P/AGR/11116/98. The authors wish also to thank Dr. Ana Maria Phillips for the English revisions.

\section{References}

[1] J. Powers, Current practices and application of descriptive methods, in: J. Piggott (Ed.), Sensory Analysis of Foods, Elsevier Applied Science Publishers, Essex (England), 1984, p. 195

[2] Z. Zhang, M. Yang, J. Pawliszyn, Anal. Chem. 66 (1994) 844A.

[3] Z. Zhang, J. Pawliszyn, Anal. Chem. 65 (1993) 1843

[4] J. Ai, Anal. Chem. 69 (1997) 1230.

[5] J. Ai, Quantitation by SPME before reaching a partition equilibrium, in: J. Pawliszyn (Ed.), Applications of Solid Phase Microextraction, RSC, Hertfordshire, UK, 1999, pp. 22-37.

[6] Flavors \& Fragrances, Aldrich's Catalog, International Edition, 2000.

[7] S. Vichi, L. Pizzale, L. Conte, S. Buxaderas, E. López-Tamames, J. Agric. Food Chem. 51 (2003) 6572.

[8] S. Vichi, A. Castellote, L. Pizzale, L. Conte, S. Buxaderas, E. López-Tamames, J. Chromatogr. A 983 (2003) 19.

[9] J. Reiners, W. Grosch, J. Agric. Food Chem. 46 (1998) 2754.

[10] M. Morales, R. Aparício, J. Rios, J. Chromatogr. A 668 (1994) 455.

[11] L. Ribeiro, Caracterização do aroma de azeites virgens com atributos positivos e negativos, Ph.D. Thesis Presented to Universidade Nova de Lisboa, Faculdade de Ciências e Tecnologia, Lisboa, Portugal, 2005.

[12] A. Matich, D. Rowan, N. Banks, Anal. Chem. 68 (1996) 4114

[13] J. Pawliszyn, Solid Phase Microextraction, Theory and Practice, Wiley-VCH, New York, 1997.

[14] L. Ribeiro, A. Costa Freitas, M.D.R. Gomes da Silva, Headspace solid phase microextraction for the characterization of volatile compounds in olive oils, in: Proceedings of the 25th International Symposium on Capillary Chromatography, Riva del Garda, Italy, May, 2002.

[15] D. Roberts, P. Pollien, C. Milo, J. Agric. Food Chem. 48 (2000) 2430. 